\title{
Dispersal of aquatic invertebrates by lesser black-backed gulls and white storks within and between inland habitats
}

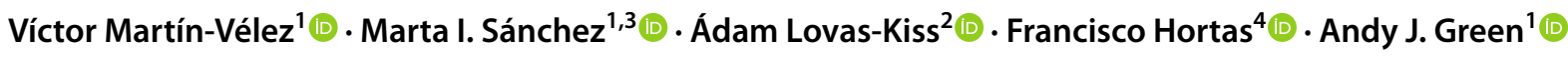

Received: 17 September 2021 / Accepted: 29 November 2021 / Published online: 15 December 2021

(c) The Author(s) 2021

\begin{abstract}
Waterbirds can transport aquatic invertebrates internally, contributing to metapopulation dynamics between aquatic habitats in a terrestrial matrix. However, research into this dispersal process to date has focused on individual field sites or laboratory studies. We investigated the invertebrates dispersed by endozoochory by the lesser black-backed gull Larus fuscus wintering in Andalusia, south-west Spain in 2016-2017, comparing seven sites interconnected by their movements, with different degrees of anthropogenization [three landfills, two saltpan complexes, a natural lake, and a large $\left(370 \mathrm{~km}^{2}\right)$ ricefield area]. In the ricefields, we also compared invertebrates dispersed by gulls with those dispersed by the larger white stork Ciconia ciconia. A total of 642 intact invertebrates and their propagules (mainly plumatellid bryozoans, cladocerans, and other branchiopods) were recorded in excreta (faeces and pellets) from gulls and storks. A greater diversity and abundance of invertebrates were recorded in ricefields, notably 43 individuals of the alien snail Physella acuta. One snail was still alive in a gull pellet 3 weeks after being stored in a fridge. This represents the first record of snail dispersal within waterbird pellets. Viability was also confirmed for the cladoceran Macrothrix rosea recorded in ricefields, and the alien brine shrimp Artemia franciscana recorded mainly in saltpans. In ricefields, gulls and pellets had significantly fewer propagules and fewer taxa per gram of excreta than storks and faeces, respectively. Through their high mobility, gulls and storks can disperse invertebrates between different natural and artificial habitats, and even to landfills. They can promote metapopulation dynamics for native bryozoans and branchiopods, but also the spread of invasive snails and brine shrimp.
\end{abstract}

Keywords Artemia $\cdot$ Cladocera $\cdot$ Endozoochory $\cdot$ Gastropoda $\cdot$ Waterbirds

\section{Introduction}

Movement between isolated water bodies represents an important challenge for aquatic organisms. With the exception of adult insects, most aquatic invertebrates lack a

Víctor Martín-Vélez

victormartin_velez@hotmail.com

1 Department of Wetland Ecology, Estación Biológica de Doñana, CSIC, Américo Vespucio 26, 41092 Seville, Spain

2 Department of Tisza River Research, Wetland Ecology Research Group, Centre for Ecological Research, Bem tér 18/C, Debrecen 4026, Hungary

3 Departamento de Biología Vegetal y Ecología, Facultad de Biología, Universidad de Sevilla, 41012 Seville, Spain

4 Instituto Universitario de Investigación Marina (INMAR), Campus de Excelencia Internacional/Global del Mar (CEI-MAR), Universidad de Cádiz, Av. República Saharaui s/n. 11510, Puerto Real, Cádiz, Spain capacity to move actively amongst wetlands, yet broad distributions and population genetic studies indicate that local and large-scale dispersal are widespread phenomena (Bilton et al. 2001; Tesson et al. 2015; Frisch et al. 2021). This also applies to alien invertebrates such as freshwater snails (e.g., Physella acuta) and brine shrimps (e.g., Artemia franciscana) (van Leeuwen et al. 2013; Horváth et al. 2018).

Since the pioneering studies of Darwin (1872), it has become widely accepted that waterbirds can transport aquatic organisms in their guts by "endozoochory", or externally by "epizoochory" (or "ectozoochory"), (Green and Figuerola 2005; Coughlan et al. 2017). They can also be important vectors for alien invertebrates (Green 2016). Compared with abiotic dispersal mechanisms (wind and water), waterbirds allow dispersal over longer distances, and often more directed towards suitable habitat (Parekh et al. 2014; van Leeuwen et al. 2012a; Viana et al. 2016).

Previous studies have demonstrated the capacity of a wide range of waterbirds to disperse freshwater 
invertebrates by endozoochory when ingesting resistant eggs of water fleas (freshwater cladocerans) or anostracans (fairy and brine shrimps), statoblasts of bryozoans (moss animals), or propagules of other organisms (Green et al. 2008; Sánchez et al. 2012; Okamura 2019; Silva et al. 2021; Briscoe et al. 2021). Sometimes, this happens when preying on primary dispersers such as fish or crayfish that are carrying the propagules (van Leeuwen et al. 2017; Lovas-Kiss et al. 2018), this being a form of "secondary dispersal". However, compared with recent advances in research into the role of waterbirds in the dispersal of plants (e.g., Lovas-Kiss et al. 2019; Martín-Vélez et al. 2021a; Sebastián-González et al. 2020), their role as dispersal vectors of invertebrates remains poorly investigated. For example, their importance as vectors for molluscs remains unclear, despite anecdotal observations and an increasing number of studies of mollusc genetics that support a key role for birds (Green and Figuerola 2005; Martin et al. 2020; Boulaassafer et al. 2020).

As yet, there are few studies comparing the rates of invertebrate endozoochory by different bird species with different morphologies in a given location (Sánchez et al. 2007; Green et al. 2008; Valls et al. 2017; Moreno et al. 2019), and even fewer comparing the rates of dispersal by a given species at different locations (Green et al. 2005). In Andalusia, southwest Spain, the lesser black-backed gull (LBBG) Larus fuscus is an opportunistic feeder which exploits and connects a wide range of habitats, including landfills, ricefields, coastal wetlands, and natural lakes (Martín-Vélez et al. 2020). The white stork Ciconia ciconia is another generalist feeder common in ricefields, landfills, and other agricultural landscapes (Tablado et al. 2010; Bécares et al. 2019). These are both migratory birds that are important members of the waterbird community in Andalusia, and whose numbers have increased markedly over the last 40 years (Rendón et al. 2008; Ramo et al. 2013). Outside the breeding period, ricefields are particularly important for both species, which feed mainly on alien crayfish Procambarus clarkii, and egest seeds in both their faeces and regurgitated pellets (MartínVélez et al. 2021a). Pellets contain undigested food items, and are normally produced at roosting sites at the end of the day. Shorter maximum gut retention times and dispersal distances are expected for propagules egested in pellets than for faeces (Martín-Vélez et al. 2021b). Like seeds, small invertebrate propagules stuck on the outside of crayfish are liable to be ingested and dispersed by these birds (LovasKiss et al. 2018). Furthermore, waterbirds can directly ingest larger invertebrates such as snails.

In this study, we aimed to investigate the potential for invertebrate dispersal by L. fuscus and C. ciconia in Andalusia, through faecal and pellet sampling. On one hand, we compared the invertebrates dispersed by $L$. fuscus and the larger $C$. ciconia as they fed in the ricefields. On the other hand, in the case of L. fuscus, their movements between ricefields and other habitats in Andalusia have recently been studied in detail (Martín-Vélez et al. 2020), and we extended our study of invertebrate endozoochory to other connected habitats, including salt pans, natural lagoons, and landfills. Apart from the ricefields, landfills are the habitats that maintain most of the connectivity in the network of habitat patches (nodes) interconnected by direct flights (links) of L. fuscus, and are strongly connected to lakes, salt marshes, and other aquatic environments (Martín-Vélez et al. 2020). We compared the invertebrates egested by gulls at different locations with differing degrees of anthropogenic impact and known connections to other locations in the connectivity network (Martín-Vélez et al. 2020).

Our main objectives were (1) to determine the differences between bird species and sample types (pellets versus faeces) in the invertebrates dispersed within ricefields, the habitat supporting the largest numbers of birds; (2) to establish the differences in invertebrates dispersed by $L$. fuscus across different habitats, including landfills visited by gulls roosting in wetland habitats; and (3) determine the viability (and further identification) of aquatic macroinvertebrates by carrying out hatching experiments.

\section{Methods}

\section{Study sites}

This study was carried out across seven sites in Andalusia used for roosting and feeding by L. fuscus, including ricefields (where $C$. ciconia were also sampled), landfills, salt pans, and a natural lake (Table 1; Fig. 1), with a known and varying extent of connectivity through direct $L$. fuscus flights (Martín-Vélez et al. 2020, 2021b). These sites are described as follows (see Martín-Vélez et al. (2020, 2021c) for more details):

- The ricefields of the Guadalquivir delta of 37,000 ha, an important part of the Doñana wetland complex (Green et al. 2018). The seeds in these samples were described by Martín-Vélez et al. (2021a). Over 10,000 L. fuscus and over 1000 C. ciconia were present during our study.

- Cetina saltpan complex (in the Gulf of Cadiz; 1100 ha) was created in 2014 and is one of the most important in Spain for salt production. Larus fuscus use it mainly as a roosting site. In the Cadiz Bay, in which Cetina Salt pan is included, an average of 5882 individuals were counted.

- Fuente de Piedra lake (1350 ha) is the largest natural lake in Andalusia and is a roosting area for over 20,000 L. fuscus in winter. See Batanero et al. (2017) for more details of this habitat. 


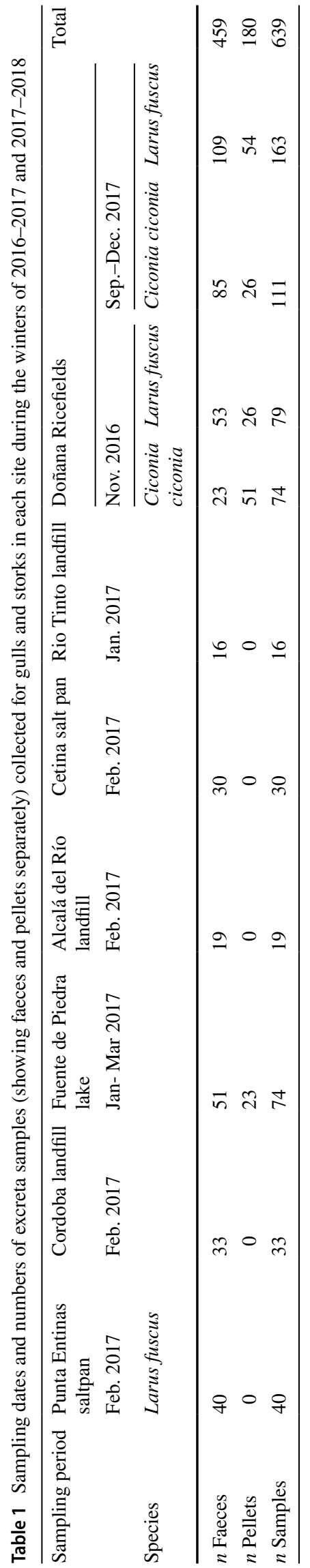

- Punta Entinas Natural Reserve (785 ha) is a complex of coastal wetlands composed of dunes, hygrophilous vegetation, and saltpans that provide refuge to a variety of birds (Luque 2003). Over 1000 L. fuscus were counted within the saltpan.

- Three landfill sites (Río Tinto landfill in Huelva, Alcalá del Río landfill in Seville and Cordoba landfill in Córdoba) are used as feeding habitat by L. fuscus, which connect these environments with wetlands used for roosting. Birds feeding at Río Tinto landfill usually roost in the Corumbel Bajo reservoir and Huelva Marshland, those at Alcalá del Río landfill roost at Gergal reservoir and in the Doñana ricefields, and those at Córdoba landfill usually roost at the Breña reservoir but sometimes at Fuente de Piedra lake (Martín-Vélez et al. 2020). Landfills provide unsuitable conditions for aquatic invertebrates and we saw no ponds or other wetlands on our visits there, so that propagules arriving to landfills are unlikely to establish.

\section{Sample collection}

Sampling for L. fuscus was conducted from November 2016 until March 2017, collecting a total of 414 samples including faeces (311) and pellets (103) (Table 1). In the ricefields, we also collected a total of 185 samples from C. ciconia, including 23 pellet and 51 faecal samples during November 2016, and 26 pellets and 85 faeces from September to November 2017 (Table 1). Fresh faeces and pellets were collected from roosting and foraging sites, where monospecific flocks were resting after feeding. Samples were taken from points separated by at least $1 \mathrm{~m}$ to ensure that they were from different individuals. To avoid contamination, we removed the surface in contact with the soil with a knife before storing the samples in separate zip bags. We stored the samples in the fridge at $4{ }^{\circ} \mathrm{C}$ until analysis (mean storage time $=35$ days, range $4-80$ days).

\section{Sample processing}

The fresh mass of pellet and faecal samples was first measured on a balance (Sartorius MSE225P) (Sartorious Lab Instruments, Goettingen, Germany). Samples were then sieved $(100 \mu \mathrm{m}$ mesh) and inspected under a stereomicroscope in Petri dishes. Invertebrate propagules [cladoceran ephippia, Artemia sp., other branchiopods, bryozoans (Plumatella spp.)] and snails were retrieved, counted, photographed, and measured (with ZEN 2-2.0 software) (CarlZeiss, Oberkochen, Germany). Seeds were also extracted at the same time (Martín-Vélez et al. 2021a). We only considered intact invertebrates or their propagules (henceforth referred to collectively as "invertebrates"), discarding broken ones, since our focus was on evidence for successful 
Fig. 1 Sampling locations in Andalusia, showing boundaries of the eight provinces. Big circles represent the sampling locations of this study, whereas small circles represent important unsampled habitats for connectivity based on Martín-Vélez et al. (2020). Dashed lines show connections between locations by direct flights. Habitat types are indicated by different colours (colour figure online)

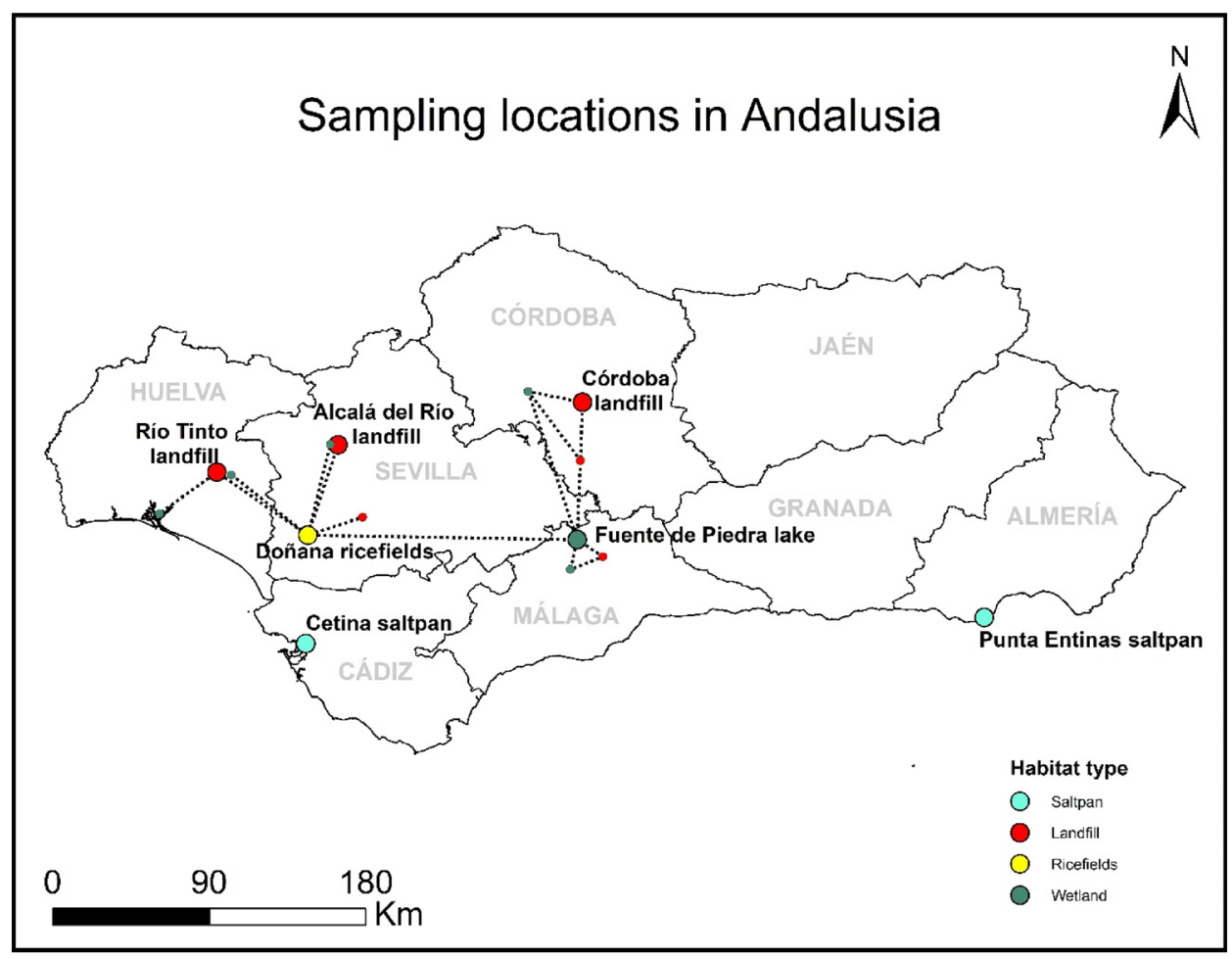

dispersal. Bryozoan statoblasts were identified to species or genus level following Wood and Okamura (2005). Cladoceran ephippia were classified into 14 different morphotypes following criteria established by Vandekerkhove et al. (2004). Classification was based on their size, gross morphology, and special features from the digital pictures taken, such as number and position of the eggs. As with plant seeds (Costea et al. 2019), gut passage changes the morphology and coloration of invertebrate propagules. Therefore, because diagnostic features (position of spines and shape of the dorsal ridge) are no longer reliable after gut passage, in most cases, we were unable to assign species or genus to morphotypes with confidence.

\section{Hatching experiments}

We followed different hatching protocols depending on the taxonomic group: (1) Artemia sp., (2) cladoceran ephippia, (3) Plumatella sp., and (4) other branchiopods. After extracting Artemia cysts from samples (protocol 1), cysts were stored in the fridge at $4{ }^{\circ} \mathrm{C}$ in dry conditions for 4-7 days until hatching experiments began. Cysts were incubated in individualized glass petri dishes with filtered seawater (25 g/l with a $\mathrm{pH}$ of 8) under continuous illumination for 48 h, following Sánchez et al. (2007). After hatching, nauplii were transferred to $60 \mathrm{~cm}^{3}$ vessels and fed with lyophilized algae Tetraselmis chuii until adults could be identified at a species level. Cladoceran ephippia (protocol 2) were stored for 107-177 days in dark conditions to break dormancy in water of $2 \%$ salinity (Ślusarczyk et al. 2019). Plumatella spp. and other branchiopods (protocol 3 and 4) were placed directly to hatch without prior storage. Ephippia, Plumatella spp. and other branchiopods were placed in plastic tubes in germination chambers with a $12 / 12$ photoperiod and $22{ }^{\circ} \mathrm{C} / 18{ }^{\circ} \mathrm{C}$ temperature conditions with water of $2 \mathrm{~g} / 1$ salinity.

\section{Data analyses}

We carried out the most detailed analyses for samples from ricefields, because of the availability of two bird species for comparison, the multiple sampling periods, and two sample types (faeces and pellets). Abundance and richness (per sample) of macroinvertebrates were taken as the dependent variable, with sample type (faeces or pellets), species (gull or stork), and period (November 2016, September 2017, October 2017, and November 2017) as fixed factors, using sample weight as a continuous variable and sampling location as a random factor (see Martín-Vélez et al. (2021a) for details). We used Generalized Linear Mixed Models (GLMM) with negative binomial error distribution and logit link function under the glmmTMB package (Magnusson et al. 2017), to account for the many samples with zero values, and overdispersion. 
We also used non-parametric statistics (Kruskal-Wallis and Dunn test) to compare the invertebrate abundance per sample across different sites in Andalusia for Larus fuscus. We tested differences in sample abundance for snails, statoblasts, ephippia, and other branchiopod eggs.

\section{Results}

\section{Invertebrates dispersed by gulls and storks}

A total of 642 intact invertebrates (including propagules) from seven different groups were recorded in excreta from gulls and storks (Tables 2 and 3). These groups represented bryozoa, cladocera, other branchiopoda, and gastropoda. Overall, $51.6 \%$ (239 of 464) of excreta samples (combining storks and gulls) contained at least one intact invertebrate (Table 2). Invertebrates were recorded in gull samples at all sites except Punta Entinas saltpans (Table 3). In ricefields, $35 \%$ of stork pellets and $67 \%$ of stork faecal samples contained at least one intact invertebrate, compared to $43 \%$ of gull pellets and $48 \%$ of gull faeces. Outside of ricefields, $23 \%$ of gull faeces contained at least one intact invertebrate.

\section{Comparison between bird species in ricefields}

The total abundance of intact invertebrates in samples was significantly related to bird species, sample type (pellet or faeces), and sample mass, with all variables having significant partial effects (Table 4). Similar results were recorded for invertebrate taxa richness (Table 4). Gulls and pellets had significantly fewer invertebrates, and fewer taxa per gram of excreta, than storks and faecal samples, respectively (Table 4). Neither abundance nor taxa richness was significantly influenced by sampling period (Table 4).

\section{Comparison of gull excreta between sites}

Differences in abundance of invertebrates between the gull samples (including faeces and pellets) at the seven sites were highly significant (Kruskal-Wallis test, $\chi^{2}=42.37, d f=5$ $p<0.0001)$. No intact propagules were recorded in the 40 samples processed from Punta Entinas saltpans, so this site was not included in this analysis or those below. Dunn post hoc tests showed that ricefields had significantly higher abundance per sample than all other sites. Other site combinations did not show significant differences. It is noteworthy that branchiopod eggs were recorded in all three landfill sites (Table 3).

Table 2 Details of intact invertebrates or their propagules found in Larus fuscus and Ciconia ciconia excreta samples from Doñana ricefields

\begin{tabular}{|c|c|c|c|c|c|c|c|}
\hline Doñana Ricefields & $n$ Samples & Cladoceran ephippia & Other branchiopod & $\begin{array}{l}\text { Plu- } \\
\text { matella } \\
\text { fungosa }\end{array}$ & Plumatella repens & Plumatella sp. & Physella acuta \\
\hline Gull faeces & 280 & 45/84 (15) & $40 / 40(5)$ & - & - & $9 / 20(5)$ & 10/17 (3) \\
\hline Gull pellets & 98 & $17 / 22(3)$ & $10 / 12(2)$ & $1 / 1(1)$ & - & 7/7 (1) & $8 * / 31(18)$ \\
\hline Stork faeces & 137 & $38 / 126(50)$ & $55 / 108$ (6) & - & $1 / 1(1)$ & $28 / 33$ (3) & $2 / 2(1)$ \\
\hline Stork pellets & 45 & $9 / 18(7)^{*}$ & $8 / 13$ (3) & - & - & $2 / 3(2)$ & $4 / 5(2)$ \\
\hline
\end{tabular}

Shown are total number of samples per site; number of samples each taxon was recorded in/total number of propagules (maximum number of propagules in a single sample)

*Cases where viability was confirmed (see main text). Underlined species are alien to the study area

Table 3 Details of intact invertebrates or their propagules found in Larus fuscus excreta samples from sampling sites across Andalusia

\begin{tabular}{|c|c|c|c|c|c|c|c|}
\hline Site & $n$ Samples & Cladoceran ephippia & $\begin{array}{l}\text { Artemia fran- } \\
\text { ciscana cysts }\end{array}$ & $\begin{array}{l}\text { Other Bran- } \\
\text { chiopod egg }\end{array}$ & $\begin{array}{l}\text { Plumatella } \\
\text { fungosa }\end{array}$ & Plumatella sp. & Physella acuta \\
\hline Alcalá del río landfill & 19 & - & - & $1 / 1(1)$ & - & - & - \\
\hline Cordoba landfill & 33 & $1 / 1(1)$ & $1 / 1(1)$ & $6 / 6(1)$ & - & - & - \\
\hline Fuente de Piedra & 75 & $4 / 4(1)$ & $4 / 4(1)$ & $5 / 6(2)$ & - & - & - \\
\hline Cetina saltpan & 30 & $1 / 1(1)$ & $8 * / 20(11)$ & $2 / 4(2)$ & - & - & - \\
\hline Rio tinto landfill & 16 & - & - & $4 / 5(2)$ & - & - & - \\
\hline Doñana ricefields & 370 & $62 / 106(15)$ & - & $62 / 70(5)$ & $1 / 1(1)$ & $16 / 27(5)$ & $18 * / 48(18)$ \\
\hline
\end{tabular}

Punta Entinas saltpan was excluded as no invertebrate taxa were recorded. Shown are total number of samples per site; number of samples each taxon was recorded in/total number of propagules (maximum number of propagules in a single sample). Underlined taxa are alien to the study area

*Cases where viability was confirmed (see main text). Underlined species are alien to the study area 
Table 4 Effects of bird species, period, sample type and weight on (A) total abundance of invertebrates and (B) taxon richness per sample from ricefields, from mixed models with a negative binomial error structure

\begin{tabular}{|c|c|c|c|c|c|}
\hline (A) Propagule abundance & Level of effect & $\beta$ & S.E & $Z$ & $p$ \\
\hline Species & Larus fuscus & -0.25449 & 0.12904 & 1.950 & 0.0486 \\
\hline \multirow[t]{3}{*}{ Period } & Sept. 2017 & 0.18130 & 0.17057 & 4.127 & 0.248 \\
\hline & Oct. 2017 & -0.06881 & 0.17994 & & \\
\hline & Nov. 2017 & 0.02758 & 0.17476 & & \\
\hline Sample mass & & 0.076 & 0.014 & 30.31 & $<0.001$ \\
\hline Sample type & Pellets & -1.07374 & 0.20168 & -5.324 & $<0.001$ \\
\hline (B) Propagule richness & Level of effect & $\beta$ & S.E & $\chi^{2}$ & $p$ \\
\hline Species & Larus fuscus & -0.23015 & 0.11287 & -2.039 & 0.0414 \\
\hline \multirow[t]{3}{*}{ Period } & Sep. 17 & 0.19718 & 0.15287 & 1.290 & 0.1971 \\
\hline & Oct. 17 & -0.06595 & 0.16043 & & \\
\hline & Nov. 17 & 0.05734 & 0.14596 & & \\
\hline Sample mass & & 0.07159 & 0.01179 & 6.073 & $<0.001$ \\
\hline Sample type & Pellets & -0.91421 & 0.17392 & -5.256 & $<0.001$ \\
\hline
\end{tabular}

Bold numbers represent significant values

Random contribution (variance): location $=0.003$. Sampling location was included as a random factor. White stork, faecal samples, and November 2016 are absent from the table, because these levels of the respective factors were aliased, and so effectively had estimates of zero. Shown for each term are the parameter estimates $(\beta)$ and their standard errors, and the main effects for each predictor variable

Bryozoan statoblasts and the alien snail Physella acuta were only recorded in ricefields, where they were significantly more abundant than in the other sites (Table 2 and 3 , Table S1, S2). One of the 43 Physella acuta individuals was recorded alive when the pellet sample was observed under the binocular microscope 24 days after collecting it on 7 th Nov 2016 and then storing it in the fridge (https://youtu.be/ JzwwcUzh1Hs; Fig. S3). Given that none of the other snails were extracted quickly from the excreta samples, it is possible that many of them were alive at the time of collection.

Cladoceran ephippia were significantly more abundant in ricefields, but were also recorded in one landfill, one lake, and one saltpan complex (Table 3, Table S3). Ephippia were classified into 14 morphotypes (see Table S4, Fig. S1), and the most abundant (morphotype $1, n=80$ ) was provisionally identified as Ceriodaphnia cf. quadrangula (Table S4, Fig. S1.1). Eggs of other branchiopods (including Artemia) were significantly rarer at Alcala del Río landfill than at Cetina saltpans (Table 3, Table S5, Fig. S2). Branchiopod eggs (including Artemia and other large Branchiopods) were present in all sites (except Punta Entinas saltpan and Alcalá del Río landfill). Specifically, Artemia cysts were mainly found in Cetina saltpan and $66.7 \%$ (20 of 30) of the samples contained at least one cyst (Table 3 ).

\section{Hatching experiments}

64\% (13 of 20) of the Artemia cysts hatched under laboratory conditions, taking on average 1.5 days to hatch and being identified upon maturity as the alien American brine shrimp Artemia franciscana. From the field season 2016-2017 in ricefields, 3 out of 36 ephippia (8\%) hatched, and all three hatchlings were Macrothrix rosea (morphotype 4). None of 79 ephippia recorded during the sampling season 2017-2018 hatched. No propagules from other taxonomic groups (other branchiopod eggs and statoblasts, see Fig. S2) hatched.

\section{Discussion}

We identified the invertebrate taxa dispersed by gulls and storks through endozoochory within the most extensive ricefield area in Spain during the autumn migration and overwintering period. We also found spatial variation across a range of habitats in the invertebrates dispersed by gulls, with more abundance and diversity in ricefields. However, propagules were present in all habitats, even landfills visited by birds roosting in wetlands. In ricefields, storks and gulls dispersed similar invertebrates, although stork excreta had a higher density of dispersed organisms. Previous work (see "Introduction") has focused on endozoochory by Anatidae (ducks, geese, and swans) and charadriiformes (shorebirds), and our findings add to growing evidence that dispersal of invertebrates by migratory waterbirds is a ubiquitous ecological process. Furthermore, the gulls and storks are likely to have also been dispersing microbes such as rotifers and ciliates not 
quantified by our methods (Moreno et al. 2019; Silva et al. 2021).

\section{Macroinvertebrate dispersal within ricefields}

The dynamism and the semi-permanent, shallow, productive aquatic conditions of the ricefields provide a suitable habitat for many cosmopolitan species of macroinvertebrates with or without resistant propagules. As for plant seeds (MartínVélez et al. 2021a), the main pathway of invertebrate dispersal by $C$. ciconia and $L$. fuscus within and away from ricefields is likely to be secondary dispersal of propagules carried by alien crayfish ( $P$. clarkii) ingested by the birds during the rice harvest (see also Lovas-Kiss et al. (2018)). Given the small size of the propagules recorded, it seems unlikely that gulls or storks would be actively foraging on them. In contrast, it is likely that the alien snails dispersed were large enough to be ingested deliberately as prey, just as waste rice grain is also consumed by gulls and storks (Martín-Vélez et al. 2021a).

Lovas-Kiss et al. (2018) previously reported three Cladoceran taxa in L. fuscus excreta from the Doñana ricefields, but not including $M$. rosea which we hatched from ephippia. Only $M$. rosea hatched in our study, and this is a cosmopolitan species common in ponds or lakes rich in organic matter (Huang et al. 2011). Seed viability has been shown to reduce with increasing storage time within the same study area (Martín-Vélez et al. 2021a). Similarly, storage procedures during our study may have reduced the rate of hatching of invertebrate propagules compared to natural conditions. Lovas-Kiss et al. (2018) did report Ceriodaphnia cf. quadrangular, which is likely to correspond to our most abundant morphotype 1 (Table S4). Amongst bryozoan statoblasts, we recorded both Plumatella repens and $P$. fungosa), and only the latter was reported by Lovas-Kiss et al. (2018). Therefore, apart from $M$. rosea, viable propagules of many other invertebrates (e.g., Ceriodaphnia cf. quadrangular, Plumatella spp.) are also likely to be dispersed by L. fuscus and $C$. ciconia under natural conditions in and beyond the ricefields.

After controlling for sample mass, invertebrate abundance and taxon richness were higher in stork excreta than in gulls, and higher in faeces than in pellets. This is consistent with the previous results for the same samples for seed abundance and richness (Martín-Vélez et al. 2021a). As with seeds (Martín-Vélez et al. 2021a), invertebrate propagules of a smaller size are more likely to pass through the intestines than to be regurgitated with larger undigested items. The causes of the difference between bird species are unknown, but could be related to differences in digestive efficiency, or prey ingestion as $C$. ciconia weighs about four times as much as L. fuscus and has a much larger gape. In contrast, L. fuscus is about ten times more abundant in the ricefields than $C$. ciconia (Rendón et al. 2008), so even if each individual stork disperses more propagules per day, overall the gull population is likely to disperse invertebrates in greater numbers. Furthermore, although both birds disperse similar invertebrate taxa (as observed for seeds, Martín-Vélez et al. 2021a), they have different movement patterns, so are likely to move invertebrates into different habitats. For example, when leaving ricefields gulls are more likely to fly to Fuente de Piedra lake (Fig. 1, and Martín-Vélez et al. 2021b), whereas storks are more likely to fly to the natural marshes of Doñana Natural Space (Ramo et al. 2013). Other waterbirds feeding in ricefields (e.g., ducks, shorebirds, flamingos, egrets, and ibis) are also likely to be important dispersal vectors for aquatic invertebrates. Multiple studies have now shown that resistant propagules of water fleas (freshwater cladocerans), anostracans (fairy and brine shrimps) and bryozoans (moss animals) are dispersed by a range of waterbirds through endozoochory (see "Introduction"), although to our knowledge, ours is the first study of storks.

The alien snail $P$. acuta is particularly widespread outside its native range in North America, and is considered the most cosmopolitan snail (Dillon et al. 2002; van Leeuwen et al. 2012b). An ability to disperse inside birds may help to explain its distribution and invasiveness. The dispersal mechanisms previously suggested for $P$. acuta include water (Van de Meutter et al. 2007), boats (Albrecht et al. 2009), and epizoochory on the feathers of waterbirds (Roscoe 1955), but endozoochory has not previously been considered. van Leeuwen et al. (2013) made a detailed study of $P$. acuta within the Doñana wetland complex including the ricefields (which was the only species found at the study area), and found high rates of gene flow between snail populations, as would be expected given our findings. Despite historical emphasis on epizoochory (Darwin 1872), snail endozoochory seems to be a more common mechanism than previously thought, as recent studies have demonstrated the ability of other snail taxa to survive gut passage through ducks or terrestrial birds (Cadee 2011; Wada et al. 2012; van Leeuwen et al. 2012b; Simonova et al. 2016). However, to our knowledge, our single observation of a live $P$. acuta is the first case of a snail surviving in pellets regurgitated by birds, indicating the possibility that snails may be dispersed in this manner as well as in faeces. It is possible that many other snails were alive when samples were collected, and hence, further work needs to be done to assess the real importance of waterbirds as vectors for $P$. acuta dispersal.

There is little previous information from field studies about how transport of viable invertebrates varies between excreta type (faeces vs pellets), and how this affects the viability of propagules and retention time, and consequently the quality of the dispersal (Martín-Vélez et al. 2021a). For example, propagules excreted in pellets may be expected to have increased likelihood of surviving as they avoid 
digestive processes within the intestines; alternatively, invertebrates expelled in pellets may be less viable, because they have been squeezed against hard prey items (Sánchez et al. 2005; Green et al. 2005). The type of excreta is also likely to have an important effect on the dispersal distance, which is related to gut retention time (Martín-Vélez et al. 2021a). Egestion in faeces is likely to provide a broader range of retention times and consequently dispersal distances (see Viana et al. 2013 for Artemia cysts), and faeces can be egested during flights or in feeding habitats, whereas pellets are more likely to concentrated in roosting habitats.

\section{Endozoochory by gulls at other sites}

In a study of the connectivity network between key sites for L. fuscus in Andalusia, the Doñana ricefields were the node with the highest centrality, i.e., with the highest number of connections across Andalusia (Martín-Vélez et al. 2020). Doñana ricefields, which its diverse invertebrate community of alien and native species, can be a good "source" site for dispersal of invertebrates to other habitats via birds. A modelling study taking the ricefields as source of seed dispersal by gulls estimated that seeds may reach dispersal distances beyond $150 \mathrm{~km}$, allowing a gull to transport a propagule directly from ricefields to Fuente de Piedra lake (Fig. 1, and Martín-Vélez et al. 2021b). Direct flights from the ricefields are also regularly made to the landfills at Alcalá del Río, Córdoba and Rio Tinto (Fig. 1), and it is plausible that some of the propagules we recorded there were ingested in ricefields. The presence of ephippia and other branchiopod eggs in faecal samples from gulls in landfills is evidence of longdistance dispersal, since landfills are unlikely to be suitable for these invertebrates, and these propagules seem likely to have been ingested elsewhere in aquatic environments used for roosting or drinking. A series of landfills used for foraging are highly connected by gulls to different wetlands across Andalusia (Martín-Vélez et al. 2020); particularly, large numbers of $L$. fuscus roost at Fuente de Piedra lake during winter, a hypersaline shallow lake supporting various branchiopod taxa (Garcia et al. 1997). These gulls feed mainly in four different landfills in the surroundings, including Cordoba landfill (Fig. 1, and Martín-Vélez et al. 2019).

At Cetina saltpans, gull samples showed high abundance of viable cysts of the invasive North American brine shrimp A. franciscana. Endozoochory of A. franciscana cysts was previously demonstrated for shorebirds in Andalusia such as Redshank Tringa totanus or Dunlin Calidris alpina (Green et al. 2005; Sánchez et al. 2012). This is the first study to demonstrate endozoochory of this widespread alien by a gull, although other gull species are known to prey on brine shrimp, as indicated by the existence of cestode gull parasites using Artemia as an intermediate host (Sánchez et al. 2013).

\section{Conclusions}

This study builds on previous knowledge of the role of waterbirds as vectors of dispersal for aquatic invertebrates, providing the first information for storks, and the first study to document spatial variation in endozoochory rates in different nodes of a known connectivity network between habitats used by a migratory bird. Larus fuscus and $C$. ciconia are likely to facilitate effective dispersal and colonization of invertebrates between habitats through both pellets and faeces. Global change (e.g., changes in land-use) may increase the importance of avian endozoochory as a pathway for biological invasions. Extensive transformation in land use across Andalusia in recent decades includes reductions in the extent of natural wetlands, but increases in the surface area artificial wetlands such as ricefields, fish ponds, or irrigation ponds (ZorrillaMiras et al. 2014). Our findings emphasize the potential that waterbirds have to enable invasive species to spread in their introduced range, although avian vectors are often overlooked by invasion biologists (Green 2016). Both alien molluscs such as the $P$. acuta and alien branchiopods such as $A$. franciscana are readily transported by waterbirds, especially those associated with anthropogenic, highly invaded environments such as ricefields and saltpans.

Supplementary Information The online version contains supplementary material available at https://doi.org/10.1007/s00027-021-00842-3.

Acknowledgements Support was provided by staff of the Aquatic Ecology Laboratory LEA-EBD and the Remote Sensing Lab LAST-EBD. These laboratories are certified to ISO9001:2015 and ISO14001:2015 quality and environmental management systems. Census data were provided by Programa de Seguimiento de EBD-CSIC. Logistic and technical support for fieldwork was provided by Doñana ICTS-RBD. Many volunteers contributed to fieldwork.

Author contributions VMV collected and analysed the samples, performed data analyses and figures and wrote the first draft; MIS reviewed several drafts; ÁLK identified the statoblast taxa and reviewed the draft once; FH contributed to fieldwork and sampling collection; AJG contributed with sampling design and co-wrote advanced drafts.

Funding Open Access funding provided thanks to the CRUE-CSIC agreement with Springer Nature. "La Caixa-Severo Ochoa 2016" (VMV). Ministerio de Economía, Industria y Competitividad project CGL2016-76067-P (AEI/FEDER, EU) (AJG, MIS). János Bolyai Research Scholarship of the Hungarian Academy of Sciences, New National Excellence Programme of the Ministry of Innovation and Technology ÚNKP-21-5-DE-457 and NKFIH OTKA FK-127939 and FK138698 grants (ÁLK).

Availability of data and materials http://hdl.handle.net/10261/250117. 


\section{Declarations}

Conflict of interest Authors declare no conflict of interests.

Open Access This article is licensed under a Creative Commons Attribution 4.0 International License, which permits use, sharing, adaptation, distribution and reproduction in any medium or format, as long as you give appropriate credit to the original author(s) and the source, provide a link to the Creative Commons licence, and indicate if changes were made. The images or other third party material in this article are included in the article's Creative Commons licence, unless indicated otherwise in a credit line to the material. If material is not included in the article's Creative Commons licence and your intended use is not permitted by statutory regulation or exceeds the permitted use, you will need to obtain permission directly from the copyright holder. To view a copy of this licence, visit http://creativecommons.org/licenses/by/4.0/.

\section{References}

Albrecht C, Kroll O, Terrazas E, Wilke T (2009) Invasion of ancient Lake Titicaca by the globally invasive Physa acuta (Gastropoda: Pulmonata: Hygrophila). Biol Invasions 11:1821-1826. https:// doi.org/10.1007/s10530-008-9360-9

Batanero GL, León-Palmero E, Green AJ, Rendón-Martos M, Suttle CA, Reche I (2017) Flamingos and drought as drivers of nutrients and microbial dynamics in a saline lake. Sci Rep 7:12173. https:// doi.org/10.1038/s41598-017-12462-9

Bécares J, Blas J, López-López P, Schulz H, Torres-Medina F, Flack A, Enggist P, Höfle U, Bermejo A, De la Puente J (2019) Migración y ecología espacial de la cigüeña blanca en España. Monografía no 5 del programa Migra. SEO/BirdLife, Madrid. https://doi.org/ $10.31170 / 0071$

Bilton DT, Freeland JR, Okamura B (2001) Dispersal in freshwater invertebrates. Annu Rev Ecol Syst 32(1):159-181. https://doi.org/ 10.1146/annurev.ecolsys.32.081501.114016

Boulaassafer K, Ghamizi M, Machordom A, Delicado D (2020) Phylogenetic relationships within Pseudamnicola Paulucci, 1878 (Caenogastropoda: Truncatelloidea) indicate two independent dispersal events from different continents to the Balearic Islands. Syst Biodivers 18:396-416. https://doi.org/10.1080/14772000. 2020.1771466

Briscoe AG, Nichols S, Hartikainen H, Knipe H, Foster R, Green AJ, Okamura B, Bass D (2021) High-throughput sequencing of faeces provides evidence for dispersal of parasites and pathogens by migratory waterbirds. Mol Ecol Resour. https://doi.org/10.1111/ 1755-0998.13548

Cadee GC (2011) Hydrobia as "Jonah in the Whale": shell repair after passing through the digestive tract of shelducks alive. Palaios 26:245-249. https://doi.org/10.2110/palo.2010.p10-095r

Costea M, El-Miari H, Laczkó L, Fekete R, Molnár AV, Lovas-Kiss Á, Green AJ (2019) The effect of gut passage by waterbirds on the seed coat and pericarp of diaspores lacking "external flesh": evidence for widespread adaptation to endozoochory in angiosperms. PLoS ONE 14(12):e0226551

Coughlan NE, Kelly TC, Davenport J, Jansen MA (2017) Up, up and away: bird-mediated ectozoochorous dispersal between aquatic environments. Freshw Biol 62(4):631-648. https://doi.org/10. $1111 /$ fwb. 12894

Darwin C (1872) The origin of species by means of natural selection, 6th edn. John Murray, London

Dillon RT Jr, Wethington AR, Rhett JM, Smith TP (2002) Populations of the European freshwater pulmonate Physa acuta are not reproductively isolated from American Physa heterostropha or Physa integra. Invertebr Biol 121(3):226-234

Frisch D, Lejeusne C, Hayashi M, Bidwell MT, Sánchez-Fontenla J, Green AJ (2021) Brine chemistry matters: isolation by environment and by distance explain population genetic structure of Artemia franciscana in saline lakes. Freshw Biol. https://doi.org/10. 1111/fwb.13737

Garcia CM, GarciaRuiz R, Rendon M, Niell FX, Lucena J (1997) Hydrological cycle and interannual variability of the aquatic community in a temporary saline lake (Fuente de Piedra, southern Spain). Hydrobiologia 345:131-141

Green AJ (2016) The importance of waterbirds as an overlooked pathway of invasion for alien species. Divers Distrib 22(2):239-247. https://doi.org/10.1111/ddi.12392

Green AJ, Figuerola J (2005) Recent advances in the study of longdistance dispersal of aquatic invertebrates via birds. Divers Distrib 11(2):149-156. https://doi.org/10.1111/j.1366-9516.2005.00147.x

Green AJ, Sánchez MI, Amat F, Figuerola J, Hontoria F, Ruiz O, Hortas F (2005) Dispersal of invasive and native brine shrimps Artemia (Anostraca) via waterbirds. Limnol Oceanogr 50(2):737-742. https://doi.org/10.4319/lo.2005.50.2.0737

Green AJ, Jenkins KM, Bell D, Morris PJ, Kingsford RT (2008) The potential role of waterbirds in dispersing invertebrates and plants in arid Australia. Freshw Biol 53(2):380-392. https://doi. org/10.1111/j.1365-2427.2007.01901.x

Green AJ, Bustamante J, Janss GFE, Fernández-Zamudio R, DíazPaniagua C (2018) Doñana Wetlands (Spain). In: Finlayson CM, Milton GR, Prentice RC, Davidson NC (eds) The wetland book: II: distribution, description and conservation. Springer, pp 1123-1136. https://doi.org/10.1007/978-94-007-4001-3_139

Horváth Z, Lejeusne C, Amat F, Sánchez-Fontenla J, Vad CF, Green AJ (2018) Eastern spread of the invasive Artemia franciscana in the Mediterranean Basin, with the first record from the Balkan Peninsula. Hydrobiologia 822(1):229-235. https://doi.org/10. 1007/s10750-018-3683-z

Huang X, Xinlu SHI, Sen XU, Guijie LIU, Limin MA, Zhiqiang SUN (2011) Life history characteristics of Macrothrix rosea (Jurine, 1820) (Cladocera, Macrothricidae) in laboratory conditions. J Limnol 70(2):248. https://doi.org/10.4081/jlimnol.2011.248

Lovas-Kiss Á, Sánchez MI, Molnár VA, Valls L, Armengol X, Mesquita-Joanes F, Green AJ (2018) Crayfish invasion facilitates dispersal of plants and invertebrates by gulls. Freshw Biol 63(4):392-404. https://doi.org/10.1111/fwb.13080

Lovas-Kiss Á, Sánchez MI, Wilkinson DM, Coughlan NE, Alves JA, Green AJ (2019) Shorebirds as important vectors for plant dispersal in Europe. Ecography 42(5):956-967. https://doi.org/ 10.1111/ecog.04065

Luque EG (2003) Paraje natural Punta Entinas-Sabinar (Almería): flora, vegetación y ornitofauna, vol 22. Universidad Almería

Magnusson A, Skaug H, Nielsen A, Berg C, Kristensen K, Maechler M, Brooks MM (2017) Package 'glmmTMB'. R Package Version 0.2 .0

Martin KR, Johnson PTJ, Bowerman J, Li J (2020) Biogeography of the freshwater gastropod, Planorbella trivolvis, in the western United States. PLoS ONE 15:e0235989. https://doi.org/10.1371/ journal.pone.0235989

Martín-Vélez V, Sánchez MI, Shamoun-Baranes J, Thaxter CB, Stienen EW, Camphuysen KC, Green AJ (2019) Quantifying nutrient inputs by gulls to a fluctuating lake, aided by movement ecology methods. Freshw Biol 64(10):1821-1832. https://doi. org/10.1111/fwb.13374

Martín-Vélez V, Mohring B, van Leeuwen CHA, Shamoun-Baranes J, Thaxter CB, Baert JM, Camphuysen CJ, Green AJ (2020) Functional connectivity network between terrestrial and aquatic habitats by a generalist waterbird, and implications for 
biovectoring. Sci Total Environ 705:135886. https://doi.org/10. 1016/j.scitotenv.2019.135886

Martín-Vélez V, Lovas-Kiss Á, Sánchez MI, Green AJ (2021a) Endozoochory of the same community of plants lacking fleshy fruits by storks and gulls. J Veg Sci 32(1):e12967. https://doi.org/10. $1111 /$ jvs. 12967

Martín-Vélez V, van Leeuwen CH, Sánchez MI, Hortas F, Shamoun-Baranes J, Thaxter CB, Lens L, Camphuysen CJ, Green AJ (2021b) Spatial patterns of weed dispersal by wintering gulls within and beyond an agricultural landscape. J Ecol 109(4):1947-1958. https://doi.org/10.1111/1365-2745.13619

Martín-Vélez V, Hortas F, Taggart MA, Green AJ, ÓHanlon NJ, Sánchez MI (2021c) Spatial variation and biovectoring of metals in gull faeces. Ecol Indic 125:107534. https://doi.org/10. 1016/j.ecolind.2021.107534

Moreno E, Perez-Martinez C, Conde-Porcuna JM (2019) Dispersal of rotifers and cladocerans by waterbirds: seasonal changes and hatching success. Hydrobiologia 834:145-162. https://doi.org/ 10.1007/s10750-019-3919-6

Okamura B, Hartikainen H, Trew J (2019) Waterbird-mediated dispersal and freshwater biodiversity: general insights from bryozoans. Front Ecol Evol 7:29. https://doi.org/10.3389/fevo.2019.00029

Parekh PA, Paetkau MJ, Gosselin LA (2014) Historical frequency of wind dispersal events and role of topography in the dispersal of anostracan cysts in a semi-arid environment. Hydrobiologia 740(1):51-59

Ramo C, Aguilera E, Figuerola J, Máñez M, Green AJ (2013) Longterm population trends of colonial wading birds breeding in Doñana (SW Spain) in relation to environmental and anthropogenic factors. Ardeola 60(2):305-326. https://doi.org/10.13157/ arla.60.2.2013.305

Rendón MA, Green AJ, Aguilera E, Almaraz P (2008) Status, distribution and long-term changes in the waterbird community wintering in Doñana, south-west Spain. Biol Conserv 141(5):1371-1388. https://doi.org/10.1016/j.biocon.2008.03.006

Roscoe E (1955) Aquatic snails found attached to feathers of whitefaced glossy ibis. Wilson Bull 67:66

Sánchez MI, Green AJ, Castellanos EM (2005) Seasonal variation in the diet of Redshank Tringa totanus in the Odiel Marshes, southwest Spain: a comparison of faecal and pellet analysis. Bird Study 52(2):210-216. https://doi.org/10.1080/00063650509461393

Sánchez MI, Green AJ, Amat F, Castellanos EM (2007) Transport of brine shrimps via the digestive system of migratory waders: dispersal probabilities depend on diet and season. Mar Biol 151(4):1407-1415. https://doi.org/10.1007/s00227-006-0577-9

Sánchez MI, Hortas F, Figuerola J, Green AJ (2012) Comparing the potential for dispersal via waterbirds of a native and an invasive brine shrimp. Freshw Biol 57(9):1896-1903. https://doi.org/10. 1111/j.1365-2427.2012.02852.x

Sánchez MI et al (2013) High prevalence and abundance of cestode parasites throughout the annual cycle of Artemia salina and A. parthenogenetica in coastal Spain: relationship with abundance of avian final hosts. J Parasitol 112(5):1913-1923. https://doi.org/ 10.1007/s00436-013-3347-x

Sebastián-González E, Lovas-Kiss Á, Soons MB, van den Broek B, Green AJ (2020) Waterbird seed-dispersal networks are similarly nested but less modular than those of frugivorous birds, and not driven by functional traits. Funct Ecol 34(11):2283-2291

Silva GG, Green AJ, Stenert C, Maltchik L (2021) Invertebrate dispersal by waterbird species in neotropical wetlands. Braz J Biol 84(4):177-189

Simonova J, Simon OP, Kapic S, Nehasil L, Horsak M (2016) Mediumsized forest snails survive passage through birds' digestive tract and adhere strongly to birds' legs: more evidence for passive dispersal mechanisms. J Molluscan Stud 82:422-426. https://doi.org/ 10.1093/mollus/eyw005
Ślusarczyk M, Chlebicki W, Pijanowska J, Radzikowski J (2019) The role of the refractory period in diapause length determination in a freshwater crustacean. Sci Rep 9(1):1-7. https://doi.org/10.1038/ s41598-019-48389-6

Tablado Z, Tella JL, Sánchez-Zapata JA, Hiraldo F (2010) The paradox of the long-term positive effects of a North American crayfish on a European community of predators. Conserv Biol 24(5):1230 1238. https://doi.org/10.1111/j.1523-1739.2010.01483.x

Tesson SVM, Okamura B, Dudaniec RY, Vyverman W, Löndahl J, Rushing C, Valentini A, Green AJ (2015) Integrating microorganism and macroorganism dispersal: modes, techniques and challenges with particular focus on co-dispersal. Ecoscience 22:109124. https://doi.org/10.1080/11956860.2016.1148458

Valls L, Castillo-Escriva A, Barrera L, Gomez E, Gil-Delgado JA, Mesquita-Joanes F, Armengol X (2017) Differential endozoochory of aquatic invertebrates by two duck species in shallow lakes. Acta Oecol Int J Ecol 80:39-46. https://doi.org/10.1016/j. actao.2017.03.003

Van de Meutter F, De Meester L, Stoks R (2007) Metacommunity structure of pond macroinvertebrates: effects of dispersal mode and generation time. Ecology 88:1687-1695. https://doi.org/10. 1890/06-0333.1

van Leeuwen $\mathrm{CH}$, Van der Velde G, van Groenendael JM, Klaassen M (2012a) Gut travellers: internal dispersal of aquatic organisms by waterfowl. J Biogeogr 39(11):2031-2040. https://doi.org/10. 1111/jbi.12004

van Leeuwen CH, Van Der Velde G, Van Lith B, Klaassen M (2012b) Experimental quantification of long distance dispersal potential of aquatic snails in the gut of migratory birds. PLoS ONE 7(3):e32292. https://doi.org/10.1371/journal.pone.0032292

van Leeuwen CH, Lovas-Kiss Á, Ovegård M, Green AJ (2017) Great cormorants reveal overlooked secondary dispersal of plants and invertebrates by piscivorous waterbirds. Biol Lett 13(10):20170406. https://doi.org/10.1098/rsbl.2017.0406

Van Leeuwen CH et al (2013) How did this snail get here? Several dispersal vectors inferred for an aquatic invasive species. Freshw Biol 58(1):88-99. https://doi.org/10.1111/fwb.12041

Vandekerkhove J, Declerck S, Vanhove M, Brendonck L, Jeppesen E, Conde-Porcuna JM, De Meester L (2004) Use of ephippial morphology to assess richness of anomopods: potentials and pitfalls. J Limnol 63(Suppl. 1):75-84. https://doi.org/10.4081/jlimn ol.2004.s1.75

Viana DS, Santamaria L, Michot TC, Figuerola J (2013) Migratory strategies of waterbirds shape the continental-scale dispersal of aquatic organisms. Ecography (cop) 36:430-438

Viana DS, Santamaría L, Figuerola J (2016) Migratory birds as global dispersal vectors. Trends Ecol Evol 31(10):763-775. https://doi. org/10.1016/j.tree.2016.07.005

Wada S, Kawakami K, Chiba S (2012) Snails can survive passage through a bird's digestive system. J Biogeogr 39:69-73. https:// doi.org/10.1111/j.1365-2699.2011.02559.x

Wood TS, Okamura B (2005) A new key to the freshwater bryozoans of Britain, Ireland and Continental Europe, with notes on their ecology. Ambleside Freshw Biol Assoc (sci Publ 63). https://doi. org/10.1111/j.1365-2109.2005.01399.x

Zorrilla-Miras P, Palomo I, Gómez-Baggethun E, Martín-López B, Lomas PL, Montes C (2014) Effects of land-use change on wetland ecosystem services: a case study in the Doñana marshes (SW Spain). Landsc Urban Plan 122:160-174. https://doi.org/ 10.1016/j.landurbplan.2013.09.013

Publisher's Note Springer Nature remains neutral with regard to jurisdictional claims in published maps and institutional affiliations. 